\title{
DESIGN AND ANALYSIS OF AUTOMATED SPRAY GUN FOR RH VESSEL
}

\author{
Subodh Kumar ${ }^{1}$, Mohammed Fayaz K ${ }^{2}$, R.P. Chaitanya ${ }^{3}$, Vasa S.N. Murthy ${ }^{4}$

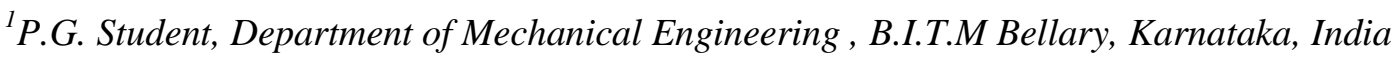 \\ ${ }^{2}$ Assistant Professor, Department of Mechanical Engineering, B.I.T.M Bellary, Karnataka, India, \\ ${ }^{3}$ Assistant Manager, Central Repair Shop, JSW Steel Ltd Vijaynagar Works, Karnataka, India \\ ${ }^{4}$ General Manager, Steel Making Shop-1, JSW Steel Ltd Vijaynagar Works, Karnataka, India
}

\begin{abstract}
In Secondary Steel Making, RH Degasser is one of the most important unit for the purification of liquid steel from the undesirable trapped gases like $\mathrm{O}_{2}, \mathrm{CO}_{2}, \mathrm{H}_{2}$ etc. It works on the principle of Server's Law. In this unit, snorkel is one of the bottom part of $\mathrm{RH}$ Vessel through which liquid steel enters into the vessel and gets degassed. Due to which snorkel inner lining gets eroded. To avoid wear and tear of the snorkel refractory lining. The gunning mass (refractory material) is used to spray manually at the tip and the outer portion of the snorkel at a distance of approx 2 meter away from the snorkel with the help of nozzle of spray gunning machine. This leads to waste of approx $40 \%$ of refractory material.
\end{abstract}

The purpose of the present work is to design and analysis of automated spray gun for RH Degasser Vessel. This gunning machine will spray the gunning mass in the inner portion of the snorkel which reduces the wear and tear of the inner snorkel lining. Hence the life of the snorkel will increase. It also saves high material loss. For this design the material selected is SS310/SS310 because of its high temperature resistance properties and good weldability. It also has good ductile property

The present work is focused on the 3D\&2D Modeling, Feasibility Check of the model and Stress Analysis on the ANSYS12.0. It also focus on the cost saving and the safe working environment

Key Words: RH Degasser, Snorkel, Spray Gun, and Refractory Powder - ***

\section{INTRODUCTION}

The hot gunning repairs of aggregates (Converter, Ladle, EAF, and RH Snorkels) are a cost saving alternative to the shut down and renewal of the complete lining. This process increases the service life of a RH Snorkels and it further results in saving of reheating energy. Due to quick repair, the number of circulating heats can be increased. The use of spray gun with the help of manipulator is necessary to improve the working condition for the operator. They further allow a more well directed repair of the corresponding position and high gunning capacity than manual gunning, which considerably reduces the repair time and the loss of heat of the aggregates. So the steel plant saves money on refractory and has lower down time and more over, the accident risks is reduced

The meaning of RH is ruhrstahl heraeus at the steel works in ruhrstahl, Germany; the first Rh-degasser was installed. Heraeus at that time was the main supplier of vacuum pumps and constructed the vacuum pump for the first $\mathrm{Rh}$ degasser

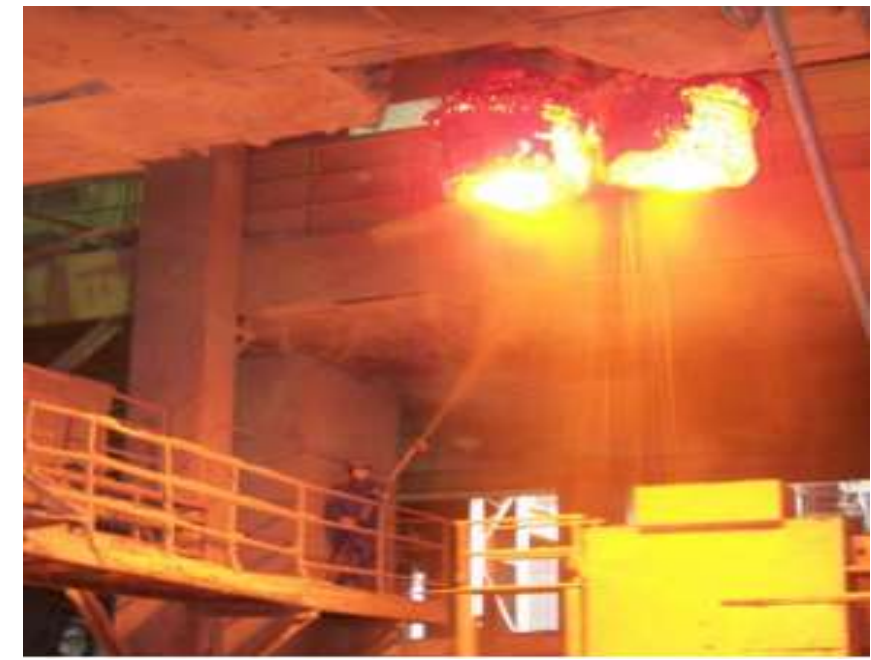

Fig-1: High material loss at manual gunning in RH Degasser

\subsection{How the RH Degassing Process Works.}

The degassing process is started after both snorkels are sufficiently immersed into the liquid steel. Before snorkel immersion the injection of inert gas, usually argon, is started in the gas pipe of the inlet snorkel. Argon acts as a lifter gas to increase the molten steel velocity which is entering into the inlet snorkel. After achieving the required immersion depth of the snorkel, the reaction vessel is evacuated by 
means of a vacuum pump system which is connected to the reaction vessel through off take duct (exhaust). The liquid steel density at $1600 \mathrm{deg} C$ is assumed at 6.94 tons per cubic meters. The atmospheric pressure exerted on the ladle surface causes the steel in the snorkels to rise to a barometric height of approximately $1.45 \mathrm{~m}$ under deep vacuum conditions.

Lift gas flow rate 1,000-4,000 N1/min

Level of lift gas injection below vessel bottom 1,200 mm Operating pressure in the $\mathrm{RH}$ vessel $0.67 \mathrm{mbar}$

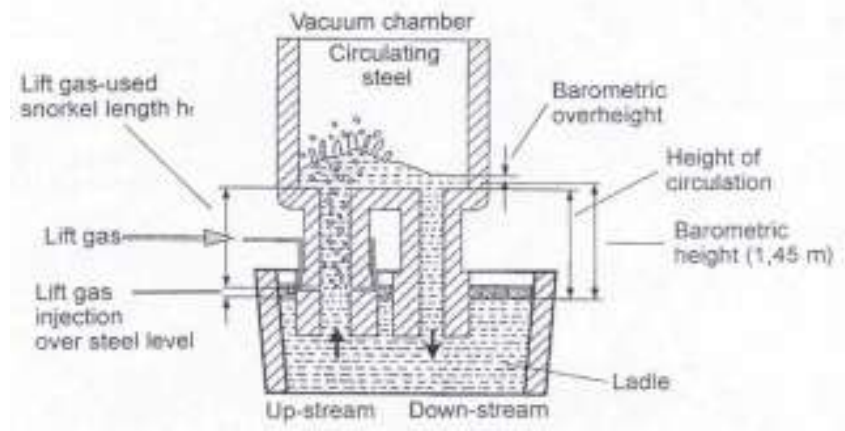

Fig -2: RH Process

\section{PROBLEM DEFINITION}

1. A real time Problem in JSW Steel Ltd, Vijaynagar Works at RH Department in Steel Melting Stop \#1

2. At present, snorkel of RH Degasser vessel is sprayed with refractory material at the tip of the snorkel only, to increase the life of snorkel.

3. Frequent wear and tear of snorkel inner surface and hence frequent changing of snorkel pair as shown in Fig (3)

4. Hazardous working environment.

5. Low efficient spraying of refractory material over the snorkel outer surface as the nozzle tip is $2.5 \mathrm{~m}$ away from snorkel.

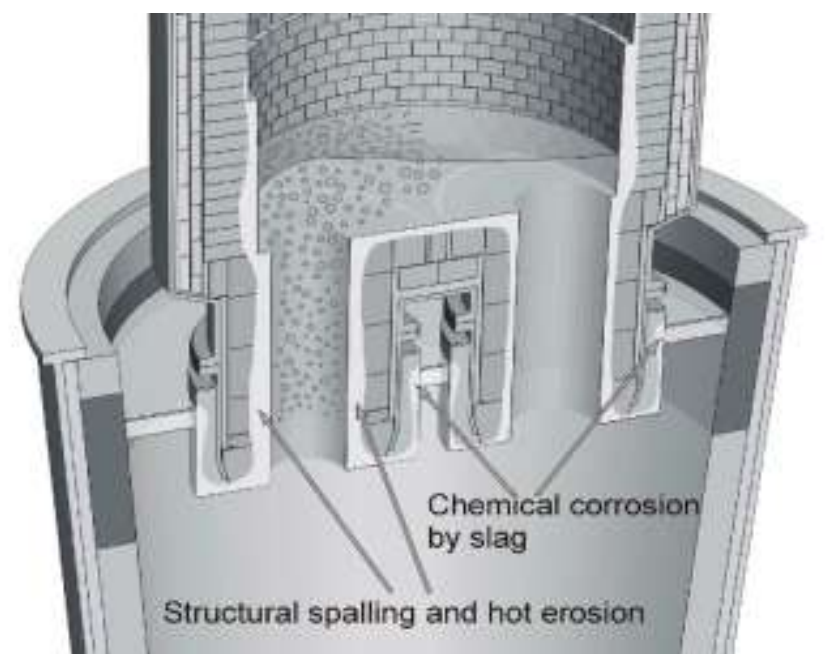

Fig 3: Wear areas of the refractory linings in RH snorkels and lower chamber

\section{OBJECTIVE}

1. To design a spray gunning machine for the spraying of refractory materials to the inner portion of the snorkel

2. To increase the life of snorkel

3. Stress Analysis of the Model

4. Cost saving by increasing the number of heats

\section{METHODOLOGY}

4.1 New Design of Spray Gun

4.2 3D Modelling

4.3 2D drafting with complete assembly

4.4 Stress Analysis

4.5 Feasibility Check

4.6 Material Selection

\subsection{D Modelling}

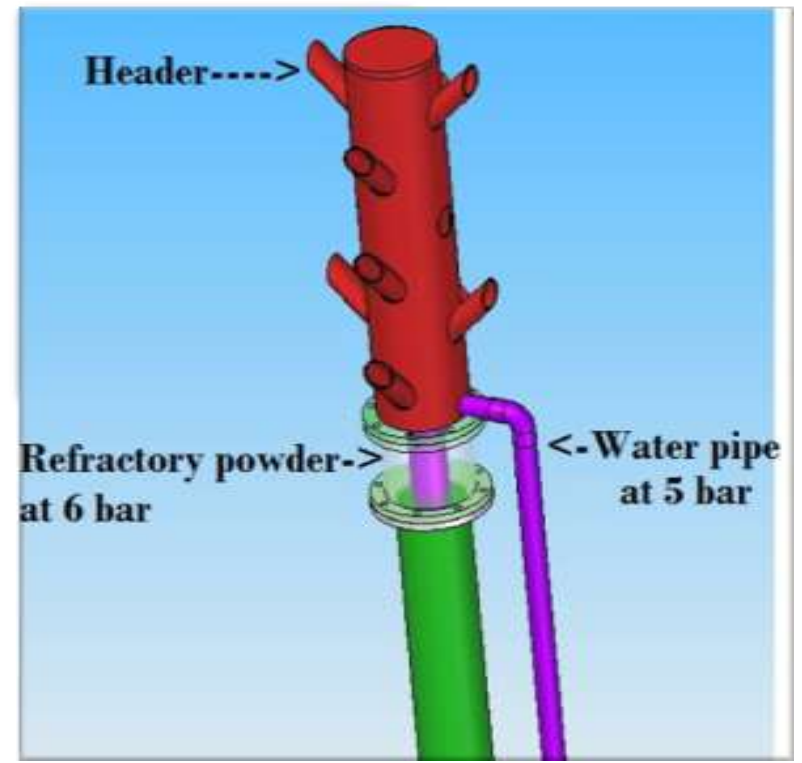

Fig -4: 3D Modelling of New Spray Gunning Machine

Table 1: Detail Design Description

\begin{tabular}{|c|c|c|c|}
\hline Parts & Colour & Specification & Purpose \\
\hline Header & Red & DN $100 * 500$ & $\begin{array}{l}\text { Mixing } \\
\text { Chamber }\end{array}$ \\
\hline Nozzle & Red & $\mathrm{DN} 40 * 50$ & $\begin{array}{l}\text { To spray on } \\
\text { the wall of } \\
\text { the Snorkel }\end{array}$ \\
\hline Water Pipe & $\begin{array}{l}\text { Deep } \\
\text { Purple }\end{array}$ & DN $20 * 1500$ & $\begin{array}{c}\text { Water flow } \\
\text { at } 5 \text { bar }\end{array}$ \\
\hline $\begin{array}{l}\text { Support } \\
\text { Pipe }\end{array}$ & Green & DN $80 * 3300$ & $\begin{array}{l}\text { To support } \\
\text { the header } \\
\text { from the } \\
\text { manipulator }\end{array}$ \\
\hline $\begin{array}{l}\text { Intermediate } \\
\text { Pipe }\end{array}$ & $\begin{array}{l}\text { Light } \\
\text { Purple }\end{array}$ & DN $80 * 100$ & $\begin{array}{l}\text { Maintenance } \\
\text { purpose }\end{array}$ \\
\hline Top Flange & White & $\begin{array}{c}\text { OD:150, ID: } \\
88.9, \\
\text { PCD: } 119\end{array}$ & $\begin{array}{c}\text { To connect } \\
\text { intermediate } \\
\text { pipe }\end{array}$ \\
\hline $\begin{array}{l}\text { Bottom } \\
\text { Flange }\end{array}$ & White & $\begin{array}{c}\text { OD:150,ID: } \\
88.9, \text { PCD: } \\
132\end{array}$ & $\begin{array}{c}\text { To connect } \\
\text { intermediate } \\
\text { pipe }\end{array}$ \\
\hline
\end{tabular}




\subsection{D drafting with complete assembly}

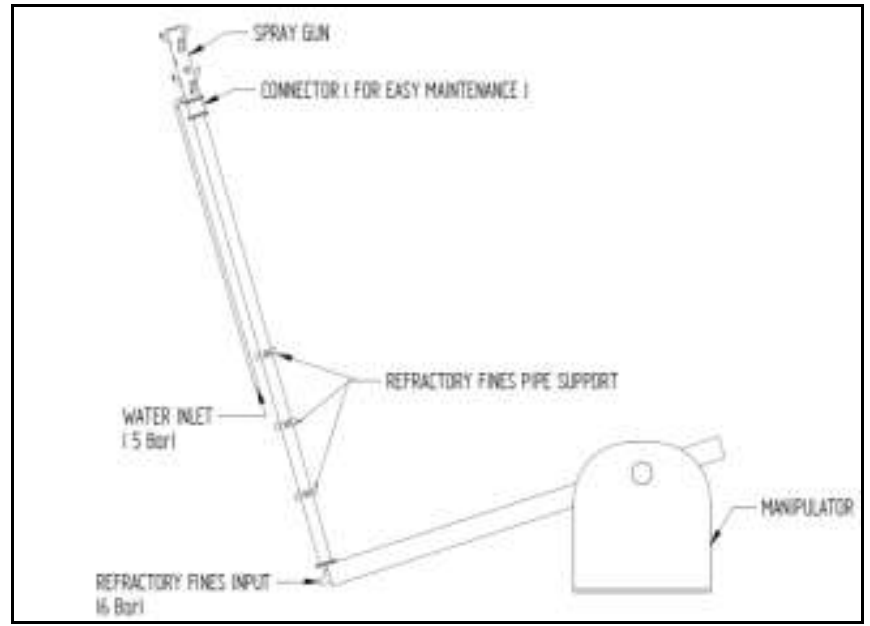

Fig.5. 2 D complete assembly with manipulator

\section{WORKING OF NEW SPRAY GUNNING}

\section{MACHINE}

The conveyer hose of the existing spray gunning machine as shown in fig5 .is connected as input to the DN40 pipe. The input is refractory fines primarily composed of magnesia chrome powder which is send to the spray gun via DN40 pipe at pressure of 6 bars. The water will enter into spray gun via DN20 pipe at a pressure of 5 bars. These refractory fines and water will mixed in spray gun and will impinge on the inner walls of the snorkel at a pressure of 5.89 bars. The whole spray gun is fixed on the tip of the manipulator through nuts and bolts. The manipulator is operated by the operator to position the spray gun at an angle of 90 degree. The paste of refractory powder and water will impinge on the inner wall of the snorkel at an angle of 45 Degree through nozzle for duration of 5-10 minutes

\subsection{STRESS ANALYSIS OF ELBOW}

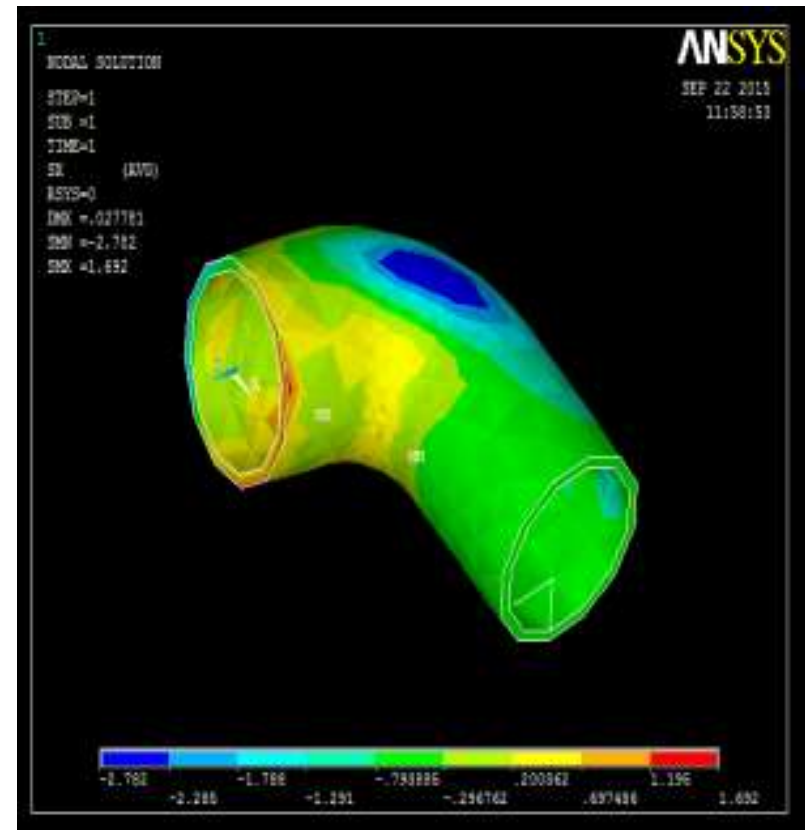

Fig 6: Stress analysis of elbow
The above fig shows the stress concentration and deformation in DN40 elbow.For this we have used ANSYS 12.0.The deformation is $.02 \mathrm{~mm}$ which is within the limit .The stress is $16.92 \mathrm{MPa}$ which is less than yield strength $205 \mathrm{MPa}$ of SS310. Hence the design will work safe

\subsection{Feasibility Check}

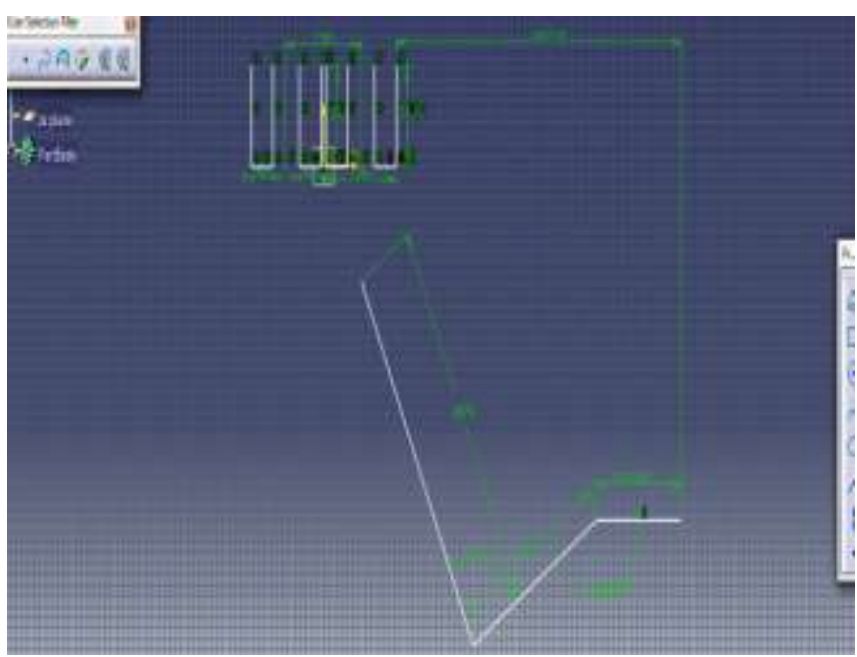

Fig- 7: Feasibility check through Catia software

The model is checked on the Catia software to determine whether the spray gun entered in to the inner portion of the snorkel without touching the inner wall of the snorkel. It assures that model will operate with the help of manipulator for the spraying of gunning mass in the inner portion of the snorkel

From the results of the Catia software, the spray gunning machine executes the above operation without touching the inner walls of the snorkel

\subsection{Material Selection}

For our design of spray gun, the selected material is Stainless Steel (SS310/SS310S) because of following properties

1. SS310 has high temperature (up to 1400 Degree Centigrade) resistance properties

2. As the sulphur gases are not present, it resists oxidation in continuous service at temperature up to 1500 Degree Centigrade

3. SS310S is used in the moist environment also

4. SS310S has Young's Modules $200 \mathrm{GPa}$ which is sufficient for our design

\section{CONCLUSIONS}

1. By designing spray gunning machine, the working life of the snorkel is increased from 35 hours to 42.5 hours. Hence the cost saved (estimated) is Rs 67.25 Lakhs Per Year

2. Working environment is safe for the operator 


\section{REFERENCES}

[1]http://sbecpl.com/products/stainless-steel/ss-310-310s/

[2].RH vacuum degassing technology posted by satyendra on oct 7, 2013 in technical.

[3].MECHANISMS OF WEAR OF REFRACTORY MATERIALS IN SNORKELS OF RH DEGASSER AND THE POSSIBILITIES FOR THEIR REDUCTION. Z. Czapka, Zak_ady Magnezytowe "Ropczyce" S.A, M. Skalska, Zak ady Magnezytowe "Ropczyce" S.A., , W. Zelik, Zak_ady Magnezytowe "Ropczyce" S.A

[4]GUNNING ROBOTS FOR THE HOT REPAIR

Christian Wolf Velco GmbH, Velbert, Germany 